\title{
Analisis Strategi Pengembangan Kepariwisataan Kabupaten Jepara
}

\author{
Mengku Marhendi a, Henry Yuliamir ${ }^{b}$, Enik Rahayu ${ }^{c}$ \\ aSekolah Tinggi Ilmu Ekonomi Pariwisata Indonesia, mengkumarhendi@gmail.com \\ bSekolah Tinggi Ilmu Ekonomi Pariwisata Indonesia, nakanoshinya72@gmail.com \\ 'Sekolah Tinggi Ilmu Ekonomi Pariwisata Indonesia, enikrahayu79@gmail.com
}

\begin{abstract}
A b s trak
Penelitian ini dilakukan bertujuan untuk mengetahui strategi pengembangan kepariwisataan di Kabupaten Jepara. Data penelitian ini diperoleh melalui teknik wawancara dengan melibatkan sebanyak enam informan. Metode analisis yang digunakan yaitu SWOT (Strength, Weakness, Opportunity, dan Threat). Berdasarkan hasil perhitungan Internal Strategic Factors Analysis Summary dan Eksternal Strategic Factors Analysis Summary diperoleh informasi penting bahwa posisi kuadran I. Posisi kuadran ini menghasilkan rekomendasi strategi progresif, menandakan bahwa kepariwisataan Kabupaten Jepara dalam kondisi yang prima dan berpeluang untuk melakukan ekspansi, mengembangkan serta memajukan sektor pariwisata di Kabupaten Jepara.
\end{abstract}

Kata Kunci: SWOT, Pengembangan Kepariwisata, IFAS, EFAS.

\section{A b s t r a c t}

This research was conducted to determine the tourism development strategy in Jepara Regency. The research data was obtained through interview techniques involving six informants. The analytical method used is SWOT (Strength, Weakness, Opportunity, and Threat). Based on the calculation results of Internal Strategic Factors Analysis Summary and External Strategic Factors Analysis Summary, important information is obtained that the position of quadrant I. This quadrant position produces progressive strategy recommendations, indicating that tourism in Jepara Regency is in excellent condition and has the opportunity to expand, develop and advance the tourism sector in the district of Jepara.

Keywords: SWOT, Tourism Development, IFAS, EFAS.

\section{Pendahuluan}

Upaya pengembangan pariwisata merupakan bagian intergral dari pengembangan pariwisata dan bagian integral dari pembangunan daerah sehingga harus dilakukan secara sistematis, terencana, terpadu, berkelanjutan dan bertanggung jawab. Memberikan perlindungan terhadap nilai-nilai agama, peninggalam sejarah, seni, budaya yang hidup dan kearifan lokal. Alasan utama dalam pengembangan pariwisata pada suatu daerah tujuan wisata, erat kaitannya dengan pembanguna perekonomian. Pengembangan kepariwisataan pada suatu daerah tuhuan wisata akan selalu diperhitungkan dengan keuntungan dan manfaat bagi masyarakat. Menurut Palupiningtyas, Mistriani, \& Wijoyo (2020) bahwa pengembangan desa wisata berdampak terhadap peningkatan ekonomi diantaranya tersedianya lapangan pekerjaan baru dan peningkatan pendapatan masyarakat.

Dewasa ini setiap daerah dituntut untuk dapat meningkatkan pertumbuhan ekonomi lokal dan sumber Pendapatan Asli Daerah guna menunjang daerah tersebut sebagai daerah mandiri. Pembangunan daerah diarahkan untuk mengembangkan potensi lokal, 
baik berupa potensi alam, potensi sosial-budaya, maupun potensi ekonomi. Salah satu daerah yang menjadikan pariwisata sebagai salah satu sumber PADnya adalah Kabupaten Jepara. Kabupaten Jepara terletak di sisi Timur jalur pantura Jawa Tengah yang bagian Barat dan Utara wilayahnya dibatasi oleh laut, sedangkan bagian Timur merupakan daerah pegunungan. Wilayah ini juga termasuk Kepulauan Karimunjawa, yakni gugusan pulau-pulau di Laut Jawa yang memiliki dua pulau terbesar yaitu Pulau Karimunjawa dan Pulau Kemujan. Sebagian besar wilayah Karimunjawa dilindungi dalam Cagar Alam Laut Karimunjawa. Kabupaten Jepara terletak di bagian utara Provinsi Jawa Tengah dan mempunyai potensi pariwisata yang dapat dikembangkan untuk memberi andil bagi peningkatan perekonomian daerah.

Berdasar pengamatan awal, potensi wisata yang ada di Kabupaten Jepara meliputi wisata alam, wisata bahari/pantai, wisata religi, wisata sejarah, wisata budaya, sentra kerajinan dan agrowisata. Potensi wisata yang dimiliki Kabupaten Jepara tersebut diharapkan dapat dikembangkan untuk mendukung perkembangan wilayah dan memberikan kontribusi yang besar terhadap peningkatan perekonomian masyarakat. Dilihat dari besarnya potensi pariwisata yang dimiliki oleh Kabupaten Jepara, yang sampai saat ini masih belum dikembangkan secara optimal baik dari kelayakannya sebagai kawasan wisata, atraksi/kegiatan wisata di dalam kawasan wisata tersebut maupun infrastruktur dari kawasan wisata tersebut, maka sangat diperlukan campur tangan baik dari pemerintah maupun pihak swasta untuk mendorong pembangunan pariwisata di Kabupaten Jepara. Beberapa kajian penelitian yang mengkaji tentang pengembangan sektor pariwisata bahwa pengembangan sektor wisata memiliki peranan penting terhadap pertumbuhan ekonomi serta terciptanya padat karya yang mampu meningkatkan penduduk lokal (Suryani, 2017; Yuningsih et al., 2019; Palupiningtyas et al., 2020; Suharyanto, et al., 2020; Lubis, et al., 2020). Namun demikian pada prinsipnya pengembangan sektor pariwisata masih perlu untuk dikembangkan melalui kerjasama yang melibatkan antara pemerintah, pihak swasta, akademisi dan masyarakat. Menurut Yuningsih et al., (2019) bahwa pengembangan sektor pariwisata masih belum optimal. Dengan demikian penelitian ini bertujuan untuk menganalisis strategi pengembangan kepariwisataan di Kabupaten Jepara.

\section{Landasan Teori}

\subsection{Sektor Pariwisata}

Berdasarkan sosio ekonomi, apabila diamati pada jumlah keterlibatan orang maupun uang yang beredar, pada prinsipnya pariwisata merupakan salah satu sektor utama perekonomian negara dan daerah. Selanjutnya berdasarkan sosio budaya, pariwisata merupakan sebuah pelestarian yang mengusung kearifan lokal yang berada pada suatu destinasi/kawasan wisata yang mampu menarik minat wisatawan untuk berkunjung (Handayani et al., 2022). Pembangunan sektor pariwisata diyakini mampu memberikan manfaat bagi masyarakat, khususnya dalam pembangunan di bidang ekonomi (Suryani, 2017). Pengembangan objek wisata tidak terlepas dari peran stakeholder. Menurut Ahmad et al., 2022) bahwa objek wisata menjadi suatu tolak ukur atau sebagai daya tarik 
wisatawan lokal maupun internasional yang menjadi fokus perhatian khususnya pemerintah.

\subsection{Strategi Pengembangan Sektor Pariwisata}

Strategi pada prinsipnya merupakan rangkaian dari perencanaan dan manajemen dalam mencapai tujuan. Perencanaan dan strategi sangat memungkinkan alternatif pemilihan tindakan-tindakan yang dianggap tepat, sesuai dengan situasi dan kondisi objek wisata (Supatmana, 2022). Sektor pariwisata telah memegang peran penting dan strategis dalam menunjang perekonomian nasional serta mampu menyerap tenaga kerja. Selain itu sektor pariwisata diyakini mampu mendorong investasi yang berdampak positif terhadap peingkatan devisa negara (Akbar et al., 2022). Terdapat tiga stakeholder yang berperan penting terhadap pengembangan pariwisata yaitu pemerintah, swasta dan masyarakat (Amalyah et al., 2016; Ginting et al., 2022).

Menurut Suwena et al., (2010); Handayani et al., (2022) bahwa terdapat empat (4) komponen utaman dalam memenuhi segala kebutuhan dan pelayanan pada kawasan/destinasi wisata yaitu attraction, accessibilities, amenities dan ancillary. Keempat komponen ini dapat berperan positif dalam mendukung strategi pengembangan kawasan wisata yang berdampak terhadap peningkatan jumlah pengunjung dan meningkatkan nilai ekonomi masyarakat.

\section{Metode}

\subsection{Jenis Penelitian dan Lokasi Penelitian}

Penelitian ini menggunakan metode deskriptif dengan melakukan kajian terhadap kinerja kepariwisataan. Pendekatan ini diprediksi mampu menggambarkan kondisi kepariwisataan yang ada di Kabupaten Jepara.

\subsection{Sumber Data dan Informan Penelitian}

Penelitian ini menggunakan data primer dan sekunder, dengan melakukan wawancara dan bantuan kuesioner yang diberikan kepada informan. Selain itu, data sekunder juga diperoleh dari studi literatur dan informasi yang bersumber dari Satuan Kerja Perangkat Daerah (SKPD) yang ada di Kabupaten Jepara. Penelitian ini menggunakan infroman sebanyak enam (6) orang, masing-masing empat (4) orang pengunjung wisatawan, satu (1) orang pengelola objek pariwisata dan satu orang dari pemerintah.

\subsection{Metode Analisis Data}

Penelitian ini menggunakan pendekatan metode analisis SWOT (Strength, Weakness, Opportunity, dan Threat). Analisis SWOT (Strengths, Weaknesses, Opportunities, and Threats) adalah metode analisis berdasarkan faktor internal dan kondisi persaingan eksternal, dan digunakan untuk membantu proses pengambilan keputusan atau menganalisis status-quo tertentu (Liu, Y., \& Suk, S. 2022). Analisis ini sering digunakan dalam bidang bisnis, serta diperluas untuk digunakan dalam pengelolaan sumber daya alam untuk menilai keputusan, proyek, atau arahan kebijakan yang diberikan secara sistematis (Liu, Y., \& Suk, S. 2022; Ghazinoory et., 2011; Houben et al., 1999; Reihanian et al., 2012). Menurut Qamaruddin et al., (2019) bahwa metode ini mampu menghasilkan 
strategi yang didasarkan pada kondisi situasional lingkungan internal dan ekternal pada objek penelitian.

\section{Hasil Analisis dan Pembahasan}

Berdasarkan hasil analisis dengan menggunakan SWOT, diperoleh informasi strategi yang disajikan pada tabel 1 .

\section{Tabel 1}

Hasil Analisis SWOT

\begin{tabular}{|c|c|}
\hline Kekuatan (S) & Kelemahan (W) \\
\hline $\begin{array}{l}\text { Terdapat cukup banyak } \\
\text { potensi pariwisata di } \\
\text { Kabupaten Jepara }\end{array}$ & $\begin{array}{l}\text { Dalam hal penyediaan atraksi wisata belum } \\
\text { dilakukan secara optimal seperti kurangnya } \\
\text { penyediaan koleksi akuarium dan kurangnya } \\
\text { informasi yang diberikan terkait koleksi } \\
\text { akuarium. }\end{array}$ \\
\hline \multirow[t]{6}{*}{$\begin{array}{l}\text { Sudah ada beberapa atraksi } \\
\text { wisata yang ide } \\
\text { pengembangannya cukup } \\
\text { bagus }\end{array}$} & $\begin{array}{l}\text { Kurangnya perawatan terhadap peralatan atraksi } \\
\text { wisata seperti peralatan di Jepara Science Center } \\
\text { yang sebagian besar dalam kondisi rusak dan } \\
\text { tidak dapat dipergunakan; di Kura-Kura Ocean } \\
\text { Park koleksi akuarium terbatas, papan-papan } \\
\text { informasi dalam kondisi rusak dan kabur, koleksi } \\
\text { karang yang mati. }\end{array}$ \\
\hline & $\begin{array}{l}\text { Kebersihan kawasan kurang terjaga. Jumlah } \\
\text { tenaga kebersihan masih kurang. Sarana } \\
\text { persampahan kecuali tong sampah masih sangat } \\
\text { kurang. }\end{array}$ \\
\hline & $\begin{array}{l}\text { Suasana pintu gerbang menuju kawasan wisata } \\
\text { belum dibangun sehingga tidak terbangun } \\
\text { suasana bahwa wisatawan memasuki kawasan } \\
\text { wisata }\end{array}$ \\
\hline & $\begin{array}{l}\text { Sarana pendukung wisata seperti musholla dan } \\
\text { toilet dalam kondisi kotor, beberapa sudah rusak, } \\
\text { tidak layak pakai dan tidak layak untuk kegiatan } \\
\text { pariwisata. Jumlah tempat duduk dan gazebo } \\
\text { masih kurang dan kondisinya masih banyak yang } \\
\text { tidak layak untuk wisata. }\end{array}$ \\
\hline & $\begin{array}{l}\text { Sarana pendukung keamanan wisata belum } \\
\text { diperhatikan, seperti gardu pandang untuk } \\
\text { keamanan kawasan tepi pantai belum ada, sarana } \\
\text { pendukung keamanan lainnya seperti pagar } \\
\text { pembatas jembatan ataupun tangga dalam kondisi } \\
\text { rusak. }\end{array}$ \\
\hline & $\begin{array}{l}\text { Sarana pariwisata seperti hotel yang berstandar } \\
\text { internasional belum banyak, sebagian besar } \\
\text { homestay belum berstandarisasi dan tidak layak } \\
\text { dijadikan penginapan. Secara umum faktor } \\
\text { kebersihan kawasan penginapan baik di luar } \\
\text { maupun di dalam masih kurang, fasilitas yang }\end{array}$ \\
\hline
\end{tabular}




\begin{tabular}{|c|c|}
\hline & $\begin{array}{l}\text { disediakan masih belum memenuhi standar } \\
\text { penyediaan akomodasi untuk pariwisata terutama } \\
\text { bagi wisatawan asing. }\end{array}$ \\
\hline & $\begin{array}{l}\text { Sarana pariwisata seperti restoran sangat terbatas } \\
\text { sehingga wisatawan kesulitan mencari tempat } \\
\text { makan dengan menu yang enak dan sehat, pilihan } \\
\text { menu yang bervariasi, dan tempat yang bersih. }\end{array}$ \\
\hline & $\begin{array}{l}\text { Banyaknya pedagang kaki lima yang menguasai } \\
\text { guna lahan kawasan dan berkembang tidak } \\
\text { teratur/tidak tertata dengan baik, dengan kualitas } \\
\text { bangunan dan tampilan yang tidak } \\
\text { memperhatikan nilai estetika. Banyaknya toko- } \\
\text { toko yang dikembangkan oleh masyarakat yang } \\
\text { tinggal berbatasan langsung dengan kawasan } \\
\text { wisata yang tidak memperhatikan nilai estetika } \\
\text { bangunan dan keserasian dengan bangunan- } \\
\text { bangunan lainnya. }\end{array}$ \\
\hline & $\begin{array}{l}\text { Baik jumlah dan kualitas atraksi maupun kegiatan } \\
\text { yang ada masih kurang bervariasi }\end{array}$ \\
\hline & $\begin{array}{l}\text { Sangat kurangnya produk hasil kerajinan lokal } \\
\text { dalam penjualan souvenir di kawasan wisata } \\
\text { menjadikan pemanfaatan kawasan wisata untuk } \\
\text { peningkatan penjualan produk lokal menjadi } \\
\text { tidak optimal. }\end{array}$ \\
\hline & $\begin{array}{l}\text { Kurangnya kreatifitas masyarakat dalam } \\
\text { berinovasi untuk menghasilkan berbagai macam } \\
\text { souvenir dengan model yang selalu berganti } \\
\text { (uptodate), yang mudah dibawa dan murah dari } \\
\text { berbagai macam kerajinan yang sudah } \\
\text { berkembang di kabupaten Jepara, serta masih } \\
\text { kurang bagusnya pengemasan souvenir yang } \\
\text { dijual mengakibatkan rendahnya keinginan } \\
\text { wisatawan untuk membeli cinderamata. }\end{array}$ \\
\hline & $\begin{array}{l}\text { Ada kawasan wisata yang terletak jauh dari kota } \\
\text { namun tidak tersedia sarana transportasi umum } \\
\text { untuk menuju kawasan wisata }\end{array}$ \\
\hline Peluang $(\mathrm{O})$ & Ancaman/Tantangan $(\mathrm{T})$ \\
\hline $\begin{array}{l}\text { Adanya keinginan } \\
\text { pemerintah untuk } \\
\text { mengembangkan kawasan } \\
\text { wisata }\end{array}$ & $\begin{array}{l}\text { Usaha pengembangan yang dilakukan oleh } \\
\text { pemerintah belum maksimal baik dari segi } \\
\text { pendanaan pembangunan maupun pengelolaan } \\
\text { kawasan }\end{array}$ \\
\hline & $\begin{array}{l}\text { Sumber daya manusia pengelola belum memiliki } \\
\text { kemampuan yang cukup, baik dalam pengetahuan } \\
\text { pengembangan kepariwisataan, pengelolaan } \\
\text { kawasan wisata, pemasaran kawasan wisata, } \\
\text { maupun kemampuan berbahasa asing }\end{array}$ \\
\hline
\end{tabular}




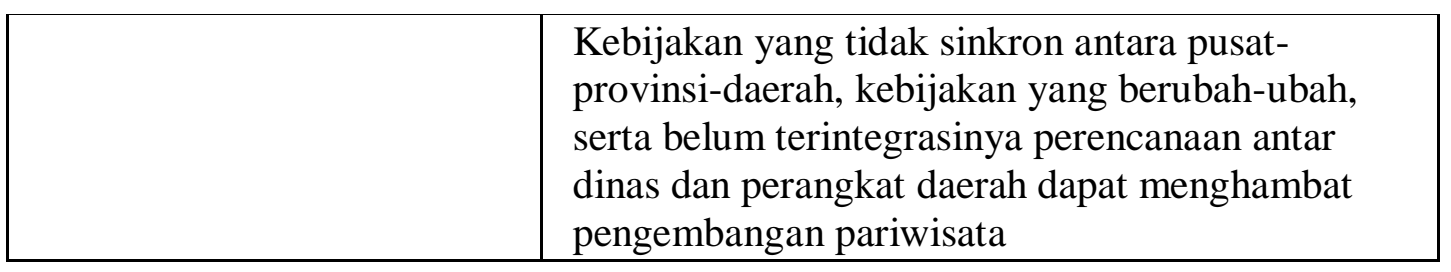

Untuk meningkatkan kenyamanan berwisata, beberapa hal yang perlu dikembangkan dari destinasi wisata yang ada di Kabupaten Jepara. Pertama, peningkatan kualitas fisik dan pelayanan, serta kuantitas sarana pariwisata seperti penginapan, tempat makan, penjualan oleh-oleh/souvenir di seluruh Kabupaten Jepara. Penginapan dapat berupa hotel, resort maupun homestay. Kedua, peningkatan kualitas dapat berupa peningkatan kebersihan, fasilitas yang disediakan, dan keramahan dari pengelola penginapan. Untuk penginapan yang dikelola oleh masyarakat seperti homestay, perlu dilakukan standarisasi minimal homestay untuk meningkatkan pelayanan dan menjamin kenyamanan wisatawan ketika menginap. Standarisasi dapat berupa standarisasi fasilitas kamar dan kualitas tempat tidur, standarisasi kualitas bangunan homestay, standarisasi ruangan yang harus disediakan dan standarisasi pelayanan yang harus diberikan. Ketiga, makan dapat berupa warung makan, restoran atau café. Peningkatan kualitas berupa peningkatan kebersihan di dalam dan di luar bangunan tempat makan, peningkatan kebersihan dalam proses pengolahan makanan dan penyajiannya, peningkatan fasilitas yang diberikan serta peningkatan pelayanannya, peningkatan kualitas bangunan dan penataan interior sehingga membuat pengunjung menjadi lebih nyaman saat berkunjung.

Selanjutnya bagian keempat, oleh-oleh/cinderamata/souvenir dapat berupa outlet penjualan yang terpusat di suatu pusat penjualan berskala kabupaten, berskala DTW atau menyebar. Untuk Kabupaten Jepara, lebih cocok dikembangkan outlet penjualan oleholeh/souvenir yang terdapat di setiap DTW dan outlet yang bersifat menyebar di setiap sentra industri. Untuk outlet souvenir di setiap DTW, lebih bersifat mengorganisasikan dan menata pedagang kaki lima dan masyarakat sekitar DTW sehingga kawasan perdagangan dan jasanya menjadi lebih rapi dan nyaman dipandang. Agar keberadaan outlet souvenir ini juga dapat meningkatkan pemasaran industri kerajinan Kabupaten Jepara maka produk-produk yang dijual harus memenuhi minimal 50\% produk lokal. Untuk outlet souvenir yang menyebar di setiap sentra industri, diperlukan rekayasa lalu lintas dengan mengatur arus lalu lintas keluar Kabupaten Jepara sehingga bisa melewati seluruh sentra industri yang ada. Selain itu juga perlu dilakukan penataan kawasan di sentra-sentra industri sehingga pada setiap jalur keluar wisata terdapat showroom, areal parkir dan lebar jalan yang mencukupi untuk lalu lintas kendaraan wisata serta sarana pendukung yang diperlukan seperti musholla, toilet dan tempat sampah. Agar dapat meningkatkan pembelian souvenir/oleh-oleh, maka persyaratan yang harus dipenuhi adalah bahwa poduk-produk yang dijual harus merupakan produk yang mudah dibawa, harganya terjangkau, dikemas secara menarik atau memiliki model yang selalu uptodate/diperbarui. Kelima, Peningkatan kualitas dan kuantitas sarana pendukung pariwisata seperti musholla, toilet, tempat duduk dan gazebo, pos penjaga keamanan dan penjaga pantai, sarana kesehatan dan sarana keuangan (ATM dan money changer), tempat 
sampah, tempat parkir dan taman. Apabila pengelola tidak mampu mengadakan seluruh sarana pendukung seperti musholla dan toilet, maka pengadaan kedua sarana ini dapat dikerjasamakan dengan masyarakat dengan persyaratan tertentu. Hal ini dilakukan untuk menjamin kenyamanan wisatawan. Untuk itu perlu dilakukan standarisasi terutama dalam hal kualitas bangunan dan perlengkapan di dalamnya.

Keenam, untuk pos penjaga keamanan sebaiknya disediakan di setiap DTW dan menggunakan seragam khusus sehingga mudah dikenali apabila dibutuhkan oleh wisatawan. Begitupula halnya dengan penjaga pantai (beach lifeguard), perlu dibuatkan pos khusus di setiap pantai di lokasi yang mudah untuk mengamati seluruh pantai, dilengkapi peralatan pendukung keamanan pantai dan mengenakan pakaian/seragam yang mudah dikenali sehingga memudahkan wisatawan yang memerlukan pertolongan. Ketujuh, sarana kesehatan juga sebaiknya disediakan di seluruh DTW terutama DTW yang potensial kedatangan wisatawan dalam jumlah besar seperti di Pantai Kartini dan Pantai Bandengan. Adapun di DTW lainnya, sarana kesehatan dapat disediakan menyatu dengan sarana kesehatan masyarakat lokal. Kedelapan, sarana keuangan terutama ATM dan money changer perlu disediakan di tempat dengan kemungkinan kebutuhan belanja yang cukup besar dan potensial didatangi pengunjung yang cukup banyak terutama wisatawan mancanegara seperti di Pantai Kartini dan Pantai Bandengan. Kesembilan, peningkatan kualitas pelayanan prasarana pendukung pariwisata terutama persampahan dan aksesibilitas kawasan wisata.

Selanjutnya pada bagian kesepuluh, peningkatan kualitas pelayanan prasarana dalam hal persampahan dapat dilakukan dengan pelibatan masyarakat dan PKL yang beraktivitas ekonomi di dalam dan sekitar kawasan wisata agar turut menjaga kebersihan. Pemerintah selaku pengelola kawasan berkewajiban membantu penyediaan sarana persampahan dan pengambilan sampah untuk diolah lebih lanjut. Dalam hal aksesibilitas kawasan wisata, perlu disediakan alat transportasi khusus yang beroperasi di dalam kawasan wisata. Bisa berupa kereta kelinci atau trem mini yang berkeliling secara reguler ke seluruh kawasan wisata. Bagian terakhir, peningkatan pengelolaan dan pelayanan kawasan. Peningkatan pengelolaan dalam hal ini termasuk pemeliharaan seluruh peralatan dan perlengkapan wisata. Peningkatan pelayanan kawasan dalam hal ini termasuk pemberian informasi yang bersifat tidak langsung seperti papan-papan informasi dan papan penunjuk jalan, serta pemberian informasi yang bersifat langsung kepada wisatawan. Untuk pemberian informasi yang bersifat tidak langsung, perlu dilakukan penataan sedemikian rupa sehingga papan penunjuk jalan/informasi mudah dilihat namun tidak mnggunakan pohon-pohon atau tanaman yang ada yang bersifat melukai tanaman. Untuk pemberian informasi yang bersifat langsung, kemampuan pengelola kawasan terutama dalam hal berbahasa asing masih perlu ditingkatkan melalui diklat bagi pengelola dan seluruh organisasi perangkat daerah yang berhubungan dengan pariwisata, serta recruitment tenaga kerja yang sudah mahir berbahasa asing dan memiliki latar belakang pendidikan pariwisata.

Dengan demikian, pengembangan sektor pariwisata dipandang perlu menjadi perhatian khusus baik kalangan pemerintah, perguruan tinggi, swasta dan masyarakat. 
Dengan memperhatikan beberapa item hasil analisis berupa strategi yang diperoleh akan sangat membantu dalam meningkatkan pertumbuhan ekonomi serta pendapatan masayarakat khususnya di Kabupaten Jepara Suryani, 2017; Yuningsih et al., 2019; Palupiningtyas et al., 2020; Suharyanto, et al., 2020; Lubis, et al., 2020).

\section{Simpulan}

Berdasarkan hasil analisis data yang telah diuraikan sebelumnya, maka dapat ditarik kesimpulan. Pertama, perlu dipertimbangkan tentang pengembangan konsep wisata edukasi (belajar menenun) dan wisata belanja produk-produk kain troso beserta turunannya. Kedua, diperlukannya dukungan pemerintah berupa infrastruktur jalan, penambahan armada angkutan umum. Ketiga, perbaikan pelayanan seperti ketepatan jadwal waktu kedatangan/keberangkatan serta pengembangan rute pelayanan terutama ke tempat-tempat wisata yang memiliki potensi untuk dikembangkan namun masih belum dikembangkan secara optimal.

Namun demikian penelitian ini memiliki keterbatasan diantaranya pertama, penggunaan informan yang jumlahnya masih terbatas. Kedua, penelitian ini dilakukan di Kabupaten Jepara, sehingga hasil penelitian ini masih terbatas untuk bisa diimplementasikan didaerah lain yang tidak memiliki karakteristik yang sama. Penelitian selanjutnya bisa menggunakan subsektor pariwisata kuliner serta berbasis budaya.

\section{Referensi}

Ahmad, F., Arman, A., \& Dunggio, S. (2022). Peran Dinas Pariwisata Kota Gorontalo Dalam pengembangan Pariwisata Dimasa Pandemi Covid-19. PROVIDER JURNAL ILMU PEMERINTAHAN, 1(1), 41-56.

Akbar, A., Harahap, R. H., \& Rujiman, R. (2022). Upaya Pengembangan Sektor Pariwisata Melalui Peran Kreativitas Pemuda. PERSPEKTIF, 11(1), 69-76.

Amalyah, R. Hamid, D \& Hakim, L. (2016). Peran Stakeholder Pariwisata Dalam Pengembangan Pulau Samalona Sebagai Destinasi Wisata Bahari. Jurnal Administrasi Bisnis. 37 (1).

Ghazinoory, S., Abdi, M., Azadegan-Mehr, M. (2011) Swot Methodology: A State-ofthe-Art Review for the Past, a Framework for the Future. J. Bus. Econ. Manag. 12, $24-48$

Ginting, G., Kismartini, K., Yuniningsih, T., \& Afrizal, T. (2022). Analisis Peran Stakeholders dalam Pengembangan Pariwisata Siosar. PERSPEKTIF, 11(1), 8-15.

Handayani, S. D., Mahadewi, N. M. E., \& Surata, I. K. (2022). Strategi Pengembangan Kawasan Wisata Masceti Gianyar dalam Peningkatan Jumlah Pengunjung dan Nilai Ekonomi. Tulisan Ilmiah Pariwisata (TULIP), 4(2), 71-83.

Houben, G., Lenie, K., Vanhoof, K. (1999). A knowledge-based SWOT-analysis system as an instrument for strategic planning in small and medium sized enterprises. Decis. Support Syst. 26, 125-135. 
Liu, Y., \& Suk, S. (2022). Influencing Factors of Azerbaijan and China's Sustainable Tourism Development Strategy under the One Belt One Road Initiative. Sustainability, 14(1), 187.

Lubis, F.R.A., Suharyanto, A., Effendy, R., Meidasari, V.E., Shahnaz, L. (2020). Role of Facebook Advertising in Promoting Tourism in Asia. International Journal of Psychosocial Rehabilitation, 24(1)

Palupiningtyas, D., Mistriani, N., \& Wijoyo, T. A. (2020). Analisis Lingkungan Internal dan Eksternal Pariwisata dalam Meningkatkan Ekonomi Masyarakat Lokal di Kabupaten Demak Jawa Tengah. Jurnal Manajemen STIE Muhammadiyah Palopo, 6(1), 43-49.

Qamaruddin, M. Y., Sapar, S., Risal, M., \& Hamid, R. S. (2019). Strategi Siapa Mau Kerja Apa dalam Pengembangan Model Quadruple Helix Sinergitas antara Pemerintah, Perguruan Tinggi, Industri, dan Masyarakat. Jurnal Manajemen STIE Muhammadiyah Palopo, 4(2).

Reihanian, A., Mahmood, N.Z.B., Kahrom, E., Hin, T.W. (2012). Sustainable tourism development strategy by SWOT analysis: Boujagh National Park. Iran. Tour. Manag. Perspect. 4, 223-228.

Suharyanto, A., Barus, R. K. I., \& Batubara, B. M. (2020). Photography and Tourism Potential of Denai Kuala Village. Britain International of Humanities and Social Sciences (BIoHS) Journal, 2(1), 100-108.

Supatmana, R. (2022). Pengembangan Daya Tarik Wisata Alam dan Buatan Berbasis Community Based Tourism Sebagai Destinasi Ungguluan di Kalibening Kabupaten Jepara. Jurnal Ekonomi, Manajemen Pariwisata dan Perhotelan, 1(1), 40-47.

Suryani, A. I. (2017). Strategi Pengembangan Pariwisata Lokal. Jurnal Spasial: Penelitian, Terapan Ilmu Geografi, dan Pendidikan Geografi, 3(1).

Suwena, I. K., Widyatmaja, I. G. N., \& Atmaja, M. J. (2010). Pengetahuan dasar ilmu pariwisata. Udayana University Press.

Yuningsih, T., Darmi, T., \& Sulandari, S. (2019). Model pentahelik dalam pengembangan pariwisata di Kota Semarang. JPSI (Journal of Public Sector Innovations), 3(2), 8493. 